\title{
Western US high June 2015 temperatures and their relation to global warming and soil moisture
}

\author{
Sjoukje Y. Philip - Sarah F. Kew · \\ Mathias Hauser • Benoit P. Guillod . \\ Adriaan J. Teuling • Kirien Whan • Peter \\ Uhe · Geert Jan van Oldenborgh \\ Received: date / Accepted: date
}

\begin{abstract}
The Western US states Washington (WA), Oregon (OR) and California (CA) experienced extremely high temperatures in June 2015. The temperature anomalies were so extreme that they cannot be explained with global warming alone. We investigate the hypothesis that soil moisture played an important role as well.

We use a land surface model and a large ensemble from the weather@home modelling effort to investigate the coupling between soil moisture and temperature in a warming world. Both models show that May was anomalously dry, satisfying a prerequisite for the extreme heat wave, and they indicate that WA and OR are in a wet-to-dry transitional soil moisture regime.

We use two different land surface-atmosphere coupling metrics to show that there was strong coupling between temperature, latent heat flux and the effect of soil moisture deficits on the energy balance in June 2015 in WA and OR. June temperature anomalies conditioned on wet/dry conditions show that both the mean and extreme temperatures become hotter for dry soils, especially in WA and OR.
\end{abstract}

Sjoukje Y. Philip · Sarah F. Kew · Kirien Whan · Geert Jan van Oldenborgh Royal Netherlands Meteorological Institute (KNMI), De Bilt, Netherlands E-mail: philip@knmi.nl

Mathias Hauser

ETH Zürich, Switzerland

Benoit P. Guillod

Environmental Change Institute, University of Oxford, Oxford, U.K.

Peter Uhe

Environmental Change Institute, University of Oxford, Oxford, U.K.

Oxford e-Research Centre, University of Oxford, UK

Adriaan J. Teuling

Hydrology and Quantitative Water Management Group, Wageningen University, Wageningen, Netherlands 


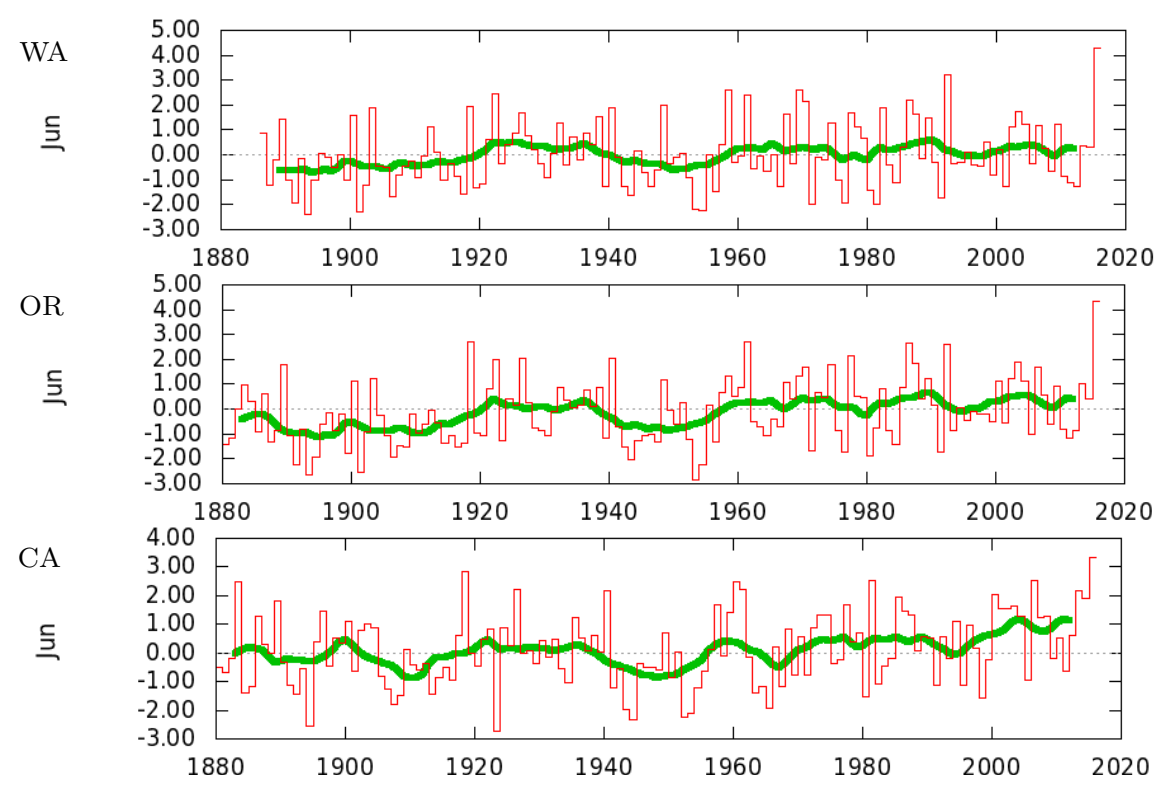

Fig. 1 June temperature anomalies. Data from GISTEMP, NASA/GISS (Hansen et al. 2010)), and anomalies are calculated with respect to the 1951-1980 climatology, for three states. The green lines show the 10-year running average.

Fitting a Gaussian model to temperatures using soil moisture as a covariate shows that the June 2015 temperature values fit well in the extrapolated empirical temperature/drought lines. The high temperature anomalies in WA and OR are thus to be expected, given the dry soil moisture conditions and that those regions are in the transition from a wet to a dry regime. CA is already in the dry regime and therefore the necessity of taking soil moisture into account is of lower importance.

Keywords temperature extremes $\cdot$ land attribution $\cdot$ global warming $\cdot$ surfaceatmosphere coupling $\cdot \pi$-metric $\cdot$ VAC-metric $\cdot$ soil moisture $\cdot$ US West Coast states

\section{Introduction}

The year 2015 was marked by record-breaking early-summer temperatures in the US Pacific states, both for individual days and locations (e.g. $45^{\circ} \mathrm{C} / 103^{\circ} \mathrm{F}$ at Chief Joseph Dam WA on June 28) and the June monthly mean state averages (see Fig. 1 for the historical series of June temperatures). In both Washington (WA) and Oregon (OR) the temperature anomaly of June 2015 is the most extreme ever recorded, and even looks like an outlier. The mean June temperature in California (CA) was also record high, although not as extreme as in WA or OR.

Heat waves can have a significant impact on human health (e.g. Guirguis et al. 2014) particularly when there is no respite from the heat during warm nights (e.g. Grize et al. 2005) and where they are uncommon, due to a lack of preparedness (e.g., lack of airconditioning) and acclimatisation, which is likely the case in WA, 


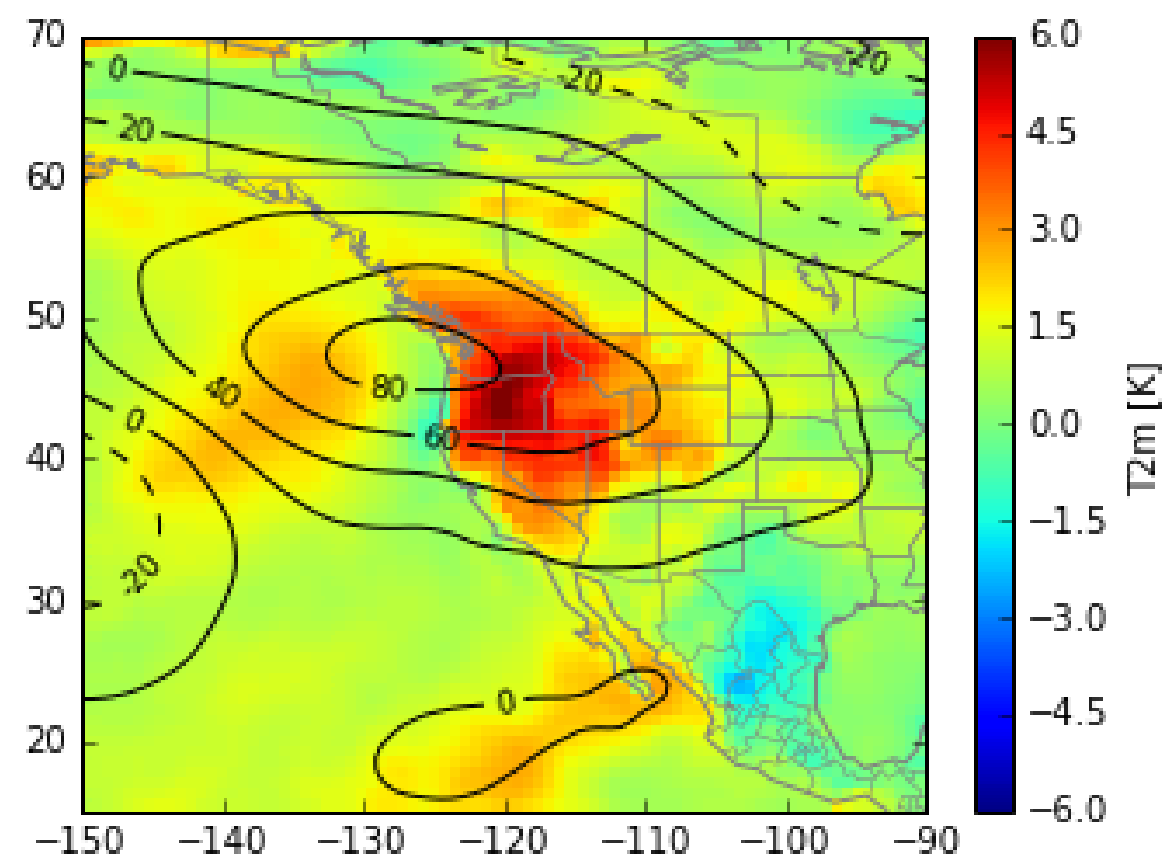

Fig. 2 Distribution of T2m temperature anomalies. Data are taken from ERA-Interim (Dee et al. 2011) and anomalies in Z500 are averaged over June 2015.

OR and CA. The combination of high temperatures and drought conditions can also facilitate the spread of wildfires. Indeed, from June to September, the region suffered numerous wildfires, with WA experiencing the largest wildfires in the state's history.

Over the past few years, numerous studies have addressed the ongoing Californian drought, including its climatic and anthropogenic controls (Swain 2015; AghaKouchak et al. 2015; Seager et al. 2015; Van Loon et al. 2016). By 2015, the drought was, however, no longer confined to CA. OR was experiencing the impacts of two years of drought, and WA had experienced the first year of drought due to very low snowpack resulting from warm, mild winter conditions. The role of extreme temperature in exacerbating the drought has been explored for the years 2012-2014, focussed on CA (e.g. Williams et al. 2015; Diffenbaugh et al. 2015). Others investigated the contribution of the global warming trend to exacerbation of drought in terms of soil moisture deficits (e.g. Seager and Hoerling 2014; Cheng et al. 2016).

In this paper, we address the origin of the exceptional June temperatures reached in 2015 in the West Coast states, and explore some of the potential mechanisms that led to them. Previous heatwave studies like Fischer et al. (2007) and Hauser et al. (2016) hypothesize that a feedback between soil moisture and the atmosphere can substantially augment extreme temperatures. Miralles et al. (2014) provided additional insight into both soil and atmosphere feedbacks, by highlighting the role of desiccating soils and atmospheric boundary layer growth 
over extended periods of time. Yin et al. (2014) explored two interpretations of the coupling between temperature and precipitation/evaporation: a temperature anomaly leading to increased evaporation and a precipitation deficit leading via higher evaporation to higher sensible heat flux, resulting in higher temperatures.

A general pre-requisite for heat waves is a persistent mid-tropospheric anticyclonic circulation anomaly, which is dynamically linked to subsidence and clear skies (Meehl and Tebaldi 2004, and references therein) and consequently to adiabatic warming, strong insolation and surface sensible heating (e.g. Miralles et al. 2012; Stegehuis et al. 2013). Indeed, the area suffering extreme June temperatures corresponded well with the form of an anomalous mid-tropospheric ridge (Fig. 2). The ERA-Interim Z500 anomaly (Fig. 2) was in itself extreme, with a return period (not shown) of more than 75 years in WA and OR. The June-averaged 700 $\mathrm{hPa}$ vertical winds reveal an anomalously strong region of subsidence over WA (return period $>1000$ years, not shown) that extends partially into OR. Although the state-averaged subsidence over Oregon was not extreme, the mid to lower tropospheric circulation was such that the air descending over WA was transported southward into OR and likely contributed to the temperature anomaly there too.

In this paper we investigate different mechanisms leading to the extreme temperatures. The influence of global warming is investigated using both observations and model data. Furthermore, we use climate models to analyse the contribution of anomalous SST conditions on temperature. Finally, we investigate the influence of anomalous soil moisture conditions (drought) on the temperature extremes through land surface-atmosphere feedbacks.

The paper is organized as follows. Section 2 outlines the datasets and methods used. In Section 3 the temperature extremes are discussed and a new hypothesis on the origin of the temperature extremes is suggested. The development of soil moisture is shown in Section 4 and the coupling of soil moisture and temperature is investigated in Section 5. Finally, we conclude in Section 6.

\section{Data and Methods}

For the analysis of surface temperature anomalies we use the National Aeronautics and Space Administration (NASA) Goddard Institute for Space Science (GISS) surface temperature analysis (GISTEMP) with $250 \mathrm{~km}$ smoothing (Hansen et al. 2010). This dataset provides monthly surface temperature anomalies from 1880 to now, has a nominal resolution of $1^{\circ} \times 1^{\circ}$ and uses $1951-1980$ as the base period. This long dataset allows us to investigate the extremity of the June 2015 temperature anomaly.

A large ensemble of hundreds of climate model simulations from the weather@home project (Massey et al. 2015) is analysed (hereafter w@h).w@h employs the Global Climate Model HadAM3P, which is downscaled to roughly $25 \mathrm{~km}$ over the Western US by the Regional Climate Model HadRM3P (see, e.g., Li et al. 2015; Mote et al. $2016 \mathrm{~b}$, for a description of the setup over the Western US). Both models share essentially the same physics and are driven by observed sea surface temperature and sea ice. Two sets of simulations have been performed: The first is an 'All Forcings' scenario, using observations in 2015. Sea surface temperature and sea ice data were obtained from the Operational Sea Surface Temperature and Sea Ice Analysis (OSTIA) dataset (Donlon et al. 2012). The second set of simulations is a 'Natural' 
scenario, in which an estimate of the changes in SST pattern due to anthropogenic forcing (CMIP5 ensemble mean, (Taylor et al. 2012)) have been subtracted from the observed 2015 OSTIA SSTs. In this scenario, sea ice is prescribed by taking the distribution from years with the highest Antarctic and Arctic sea ice extent (2012 and 1986, respectively), and a pre-industrial atmospheric composition is specified. Initialised on 1 December 2014 with restart files taken from from spin-up runs, the model simulations are run for 12 months, i.e., until the end of November 2015. Several hundred simulations for each ensemble are analysed in this paper, as well as about 130 All-forcing simulations per year from 1986-2014 .

To obtain a best estimate of soil moisture conditions and latent heat flux, we forced the Community Land Model (CLM, version 4.0; Oleson et al. (2010)) with 6 hourly ERA-Interim diagnostic and prognostic variables. The offline simulation on a $0.5^{\circ}$ grid extends from 1979-2015. This approach is similar to ERA-Interim/Land (Balsamo et al. 2015), which, however, only extends to 2010. It has been successfully applied in Orth and Seneviratne (2015); Hauser et al. (2016). The Pearson correlation for mean June soil moisture between CLM and ERA-Interim/Land for the overlapping period (1979-2010) for WA, OR and CA is 0.95, 0.94, and 0.97, respectively. Note, however, that these two soil moisture data sets have been derived with (almost) the same forcing data.

In order to determine the return periods of the monthly temperature anomalies we fit observed June mean temperatures to a Gaussian distribution. Furthermore, we investigate how the likelihood of occurrence of extreme temperatures has changed as a result of, for instance, global warming. The effects of global warming are included by allowing one parameter of the Gaussian distribution to vary, assuming a linear dependence on the (low pass filtered) global mean temperature. For temperature extremes, a reasonable first order assumption is to only allow the location parameter $\mu$ to vary with global mean temperature, as was proposed by van Oldenborgh (2007) and Otto et al. (2012). Note that this applies to observational data, while for w@h return periods are directly estimated for both ensembles (all forcings and natural).

\section{Temperature extremes in the West Coast States}

A first order explanation for the extreme temperatures in the summer of 2015 is the higher global mean temperature. When the global mean temperature rises, the magnitude and frequency of extreme temperature events often rise as well. This hypothesis can be investigated by fitting both observed and modeled June temperatures.

We fit a Gaussian distribution to the observed June temperature anomalies from 1886-2014 (i.e. excluding the month under investigation, June 2015), and allow the location parameter to vary with global mean temperature (Fig. 3). The distribution before 2015 is described well by a Gaussian distribution, as can be seen by the agreement between the observations and fitted curve.

This analysis shows that the temperatures in the summer of 2015 were indeed extreme in WA, OR and CA under the assumption that increased global mean temperature was the sole mechanism causing the heat wave. In WA, an event of the same magnitude is expected to happen at most once in 350 years in the climate of 2015 (lower bound of $95 \%$ confidence interval). The likelihood of this event has 

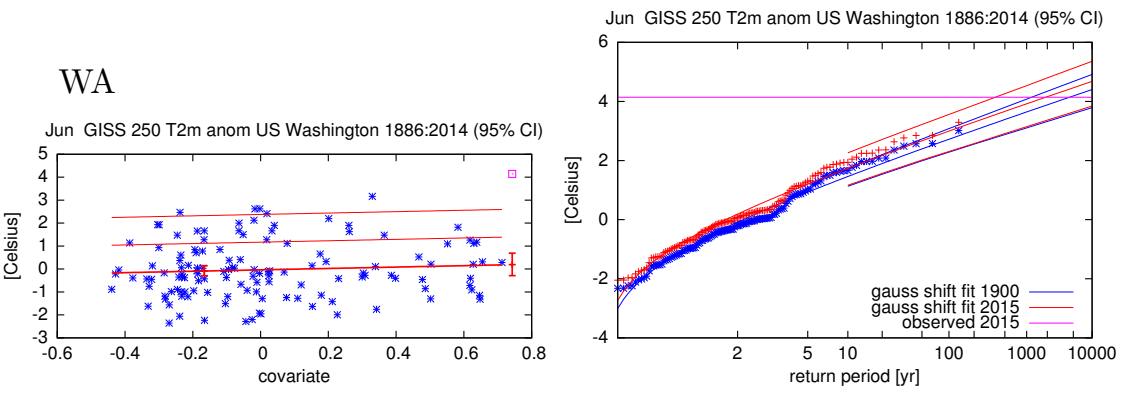

\section{OR}
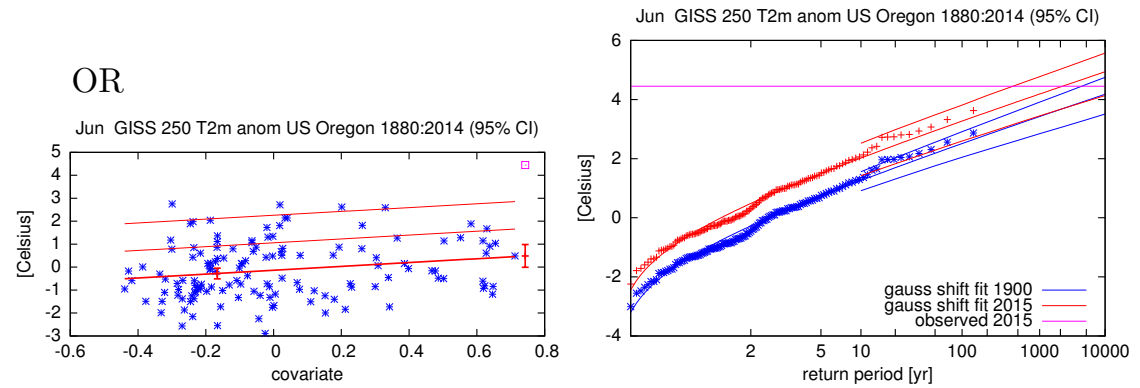

\section{$\mathrm{CA}$}
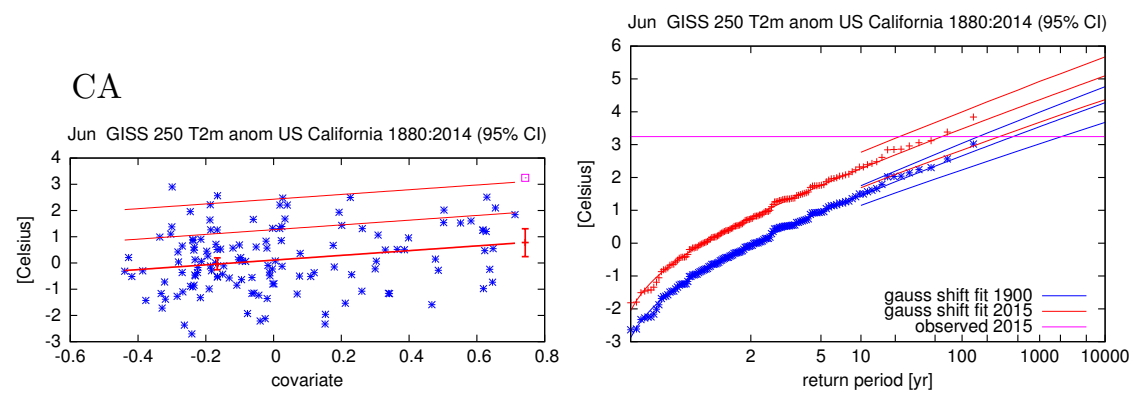

Fig. 3 Impact of changing global mean temperatures on the return period of temperature extremes. Left: Monthly GISTEMP June temperature anomalies against the change in global mean temperature. The thick line denotes the time-varying mean and the thin lines are $1 \sigma$ and $2 \sigma$ above, respectively. The purple square shows the 2015 value, which was not used in the fit, and the two vertical red lines show the $95 \%$ confidence interval of $\mu$ for the climates of 1900 and 2015. Right: Return periods for the 2015 climate (red lines) and the 1900 climate (blue lines with 95\% CI). Observations are shown twice, once shifted up to the climate of 2015 with the fitted trend (red signs), once shifted down to 1900 (blue signs).

increased by a factor of 2 since 1900. This is due to the trend excluding the year 2015, which is $0.3 \pm 0.6$ times the Global Mean Surface Temperature (GMST), however this trend is not significantly different from zero. The influence of GMST is larger in OR. The 2015 event in OR is also outside all previously measured temperatures, even after accounting for the linear trend, and the lower bound for the return period is 400 years. Due to a fitted trend of $0.8 \pm 0.6$ times the GMST, the event is now 10 (95\% confidence interval 2-90) times more likely than in 1900. The Californian temperature anomaly was less extreme in the sense that the temperature falls inside the range of observed values, once the trend has been accounted for. However, it was still extreme under the assumptions of the fit, with 
a return period of 60 years. It became $7(2-35)$ times more likely now than it was around 1900 due to a trend of $0.9 \pm 0.7$ times the GMST.

In WA and OR, the shifts in the distributions of June temperature anomalies to warmer, recent GMST conditions (using the 1880-2014 period) was small compared to the June 2015 temperature anomalies. The observed temperature anomaly remains very extreme even after accounting for this trend. This indicates that a simple shift of the distribution proportional to the rise in GMST due to greenhouse gases (Stocker et al. 2013) alone is probably not sufficient to explain the high 2015 temperatures in these states.

To further test the hypothesis that the high June 2015 temperature cannot be explained by a linear shift alone, we use the w@h ensemble. The advantage of this ensemble is that the large amount of members results in many more 'weather years' than are available from observations. This allows possible changes to be detected at the high end of the temperature distribution without making the assumption that the Gaussian distribution shifts linearly with GMST, which we made in the observational analysis.

Fig. 4 shows the return period plots for June mean temperatures. The green markers and shading show the June temperature for all years (1986-2015) for runs with all forcings ('all years'). The observed temperature anomaly (magenta line) gives an indication of the return period of the event in the w@h ensemble. We corrected for the difference in base period for GISTEMP data. Note that the ensemble is not bias-corrected (aside from comparing anomalies relative to the 'all years' mean), so the value is only a rough indication of the return period. Given that we only compare the relative results of the 'all forcings' ensemble with the 'natural' and the 'all years' ensembles, the lack of bias correction does not reduce the confidence in the risk ratios (ratios of the return periods) calculated from the ensembles. The red markers show the 2015 runs only, with all forcings and conditioned on the 2015 SST pattern. The impact of the 2015 SSTs can be seen from the difference between the green and red markers. For the blue markers, temperatures are conditioned on 2015 SST anomalies, but with natural forcings (i.e., natural greenhouse gas concentrations, and with an estimate of climate change on SST subtracted from the $2015 \mathrm{SST}$ ). The difference between the red and blue markers is thus explained by anthropogenic climate change, i.e., emissions of greenhouse gases and aerosols.

First, the w@h ensembles show that global warming has increased the chances of very high June temperatures in all three states: the red lines are to the left of the blue lines. The increase in likelihood, as given by the risk ratio (ratio of the return periods of the natural and all forcings ensembles), is a factor of about 2.2 (WA), $3.4(\mathrm{OR})$ and $2.2(\mathrm{CA})$ smaller but within the uncertainty bounds of the ratio based on the observed trends. The risk ratio also increases with temperature in all three states, as could be expected from a shift of the Gaussian distribution. Feedbacks may influence the slope of this increase, for example by making the increase steeper if hot extremes are amplified by a shift into a regime with drier soils.

The w@h ensemble also highlights the role of SSTs for this event: the difference between the green and red lines is even larger than between the blue and red lines. The probability of a hot month was much higher, given the sea surface temperatures that forced these 2015 experiments. 
WA

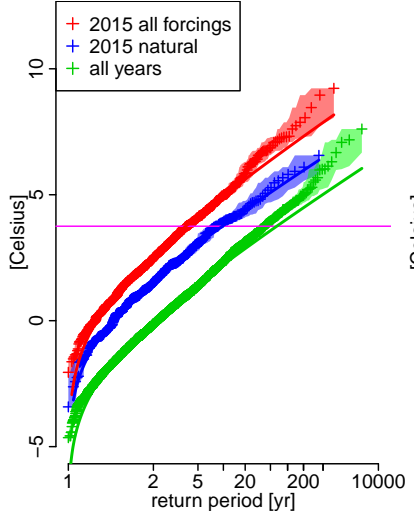

OR

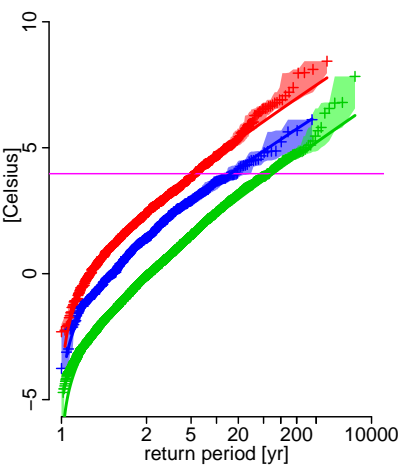

CA

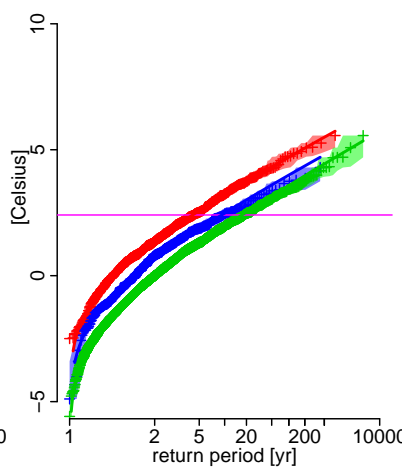

Fig. 4 Return periods of June temperature anomalies in the w@h ensemble for the three states. The green markers show results for all years (1986-2015, all forcings). The red and blue markers are simulations for 2015, conditioned on the SST patterns of 2015, for the all and natural forcings ensembles, respectively. Error margins (shading) are obtained from the 2.5$97.5 \%$ range from 1000 bootstrap samples. The horizontal line shows the observed temperature anomaly (GISTEMP). The red, blue and green lines indicate fits to Gaussian distributions.

In the w@h ensemble we have more 'weather years' than in the observations, thus, the upper tails of the return periods extend to higher temperatures than for observations. The upper tails of the return periods for WA and OR in the all forcings experiments differ from the rest of the distribution: they do not follow a Gaussian distribution, in contrast to the natural forcing experiments (and in contrast to California). In other words, the probability density function (PDF) of the temperatures does seem to change with global warming: the temperatures are higher than expected for return periods larger than about 20 years in the current climate.

For the shown return period plots of the observed temperatures, we assumed that the PDFs shift linearly with global mean temperature. However, when a different thermodynamic regime has been entered, then this assumption is not appropriate any more. Feedbacks are one mechanism that may influence the slope of this increase, for example by making the increase steeper if hot extremes are amplified by a shift into a regime with drier soils. Thus, our new hypothesis is that soil moisture plays an important role as well. For instance, a shift into a drier regime in WA, which is usually wet, may lead to enhanced temperature extremes and therefore change the PDF. In the next sections we investigate the evolution of soil moisture (Section 4) and the influence of soil moisture deficits on the observed temperatures (Section 5).

\section{Soil moisture deficits in the western states}

Soil moisture is an important variable during droughts. Apart from its relevance to some sectors such as agriculture, soil moisture has the ability to influence the atmosphere by altering the partitioning of the energy available at the land surface 
into sensible (SH) and latent (LH) heat fluxes (Seneviratne et al. 2010), particularly in transitional regions between wet and dry climates. In these regions, soil moisture can feedback onto temperature (via SH) and humidity (via LH) in the boundary layer, and thus also potentially on precipitation (Guillod et al. 2015, e.g.,). In addition, soil moisture is a useful drought indicator because it integrates the effect of precipitation and evaporation over time scales of a few weeks to months. In Section 5, land surface-atmosphere energy feedbacks will be discussed.

In this section, we examine the temporal evolution of 2015 soil moisture in the context of its recent climatology for the three western states using the land surface model CLM. We then examine the potential influence of SSTs and global warming in contributing to the dry soils using the w@h simulations.

\subsection{Observed soil moisture deficits}

Due to a lack of daily, gridded soil moisture observations, we use CLM, forced by the ERA-Interim reanalysis, as a state of the art estimate for soil moisture. Fig. 5 shows the yearly time series of daily soil moisture calculated by CLM (upper 1m of soil, upper $10 \mathrm{~cm}$ of soil shows similar time series) for each state, expressed as normalized anomalies. In CA, the three most recent years (2013-2015) have been anomalously dry in all seasons, while in WA and OR this was mostly restricted to summer months, or spring to autumn in the case of 2015. Interestingly, soil moisture increased to average conditions at the end of 2014 in all states but went back to dry conditions in March 2015. The most outstanding period is the summer of 2015 with by far the lowest soil moisture anomalies of the whole 1979-2015 period in both WA and OR. The dryness at the end of May provided a good base for a heatwave, amplified by further drying in June.

\subsection{Impact of SST forcing and internal variability on soil moisture}

Soil moisture in w@h model data provides an ideal framework to investigate the effect of SSTs on soil moisture, and compare this effect to internal variability. Here, we refer to internal variability as the chaotic variability in the atmosphere alone, i.e., excluding the oceanic variability which is prescribed in w@h and thus considered as a forcing component. We analyse our w@h simulations with all forcings from 1986-2015 and investigate monthly normalised anomalies of state-averaged soil moisture (weighted average with an exponential decay function over the root zone; this includes roughly the upper $1 \mathrm{~m}$ of the soil). Differences in the mean soil moisture between each year are driven by the SSTs, while differences between ensemble members in a given year result from chaotic variability. The ensemble means in each year (see Supplementary Figure S1) indicate no significant impact of SSTs in 2013, followed by a dry period in the first half of 2014 in all three states. Soil moisture then returned back to average, with a new strong drying in 2015 in WA and OR but not in CA.

These results indicate that the SSTs increased the chance of a dry spring in 2015 in WA and OR. However, the variability between ensemble members is large, and more interesting is the behaviour of the dry tail of the ensemble members. In other words, we would like to investigate whether, in cases when internal variability 


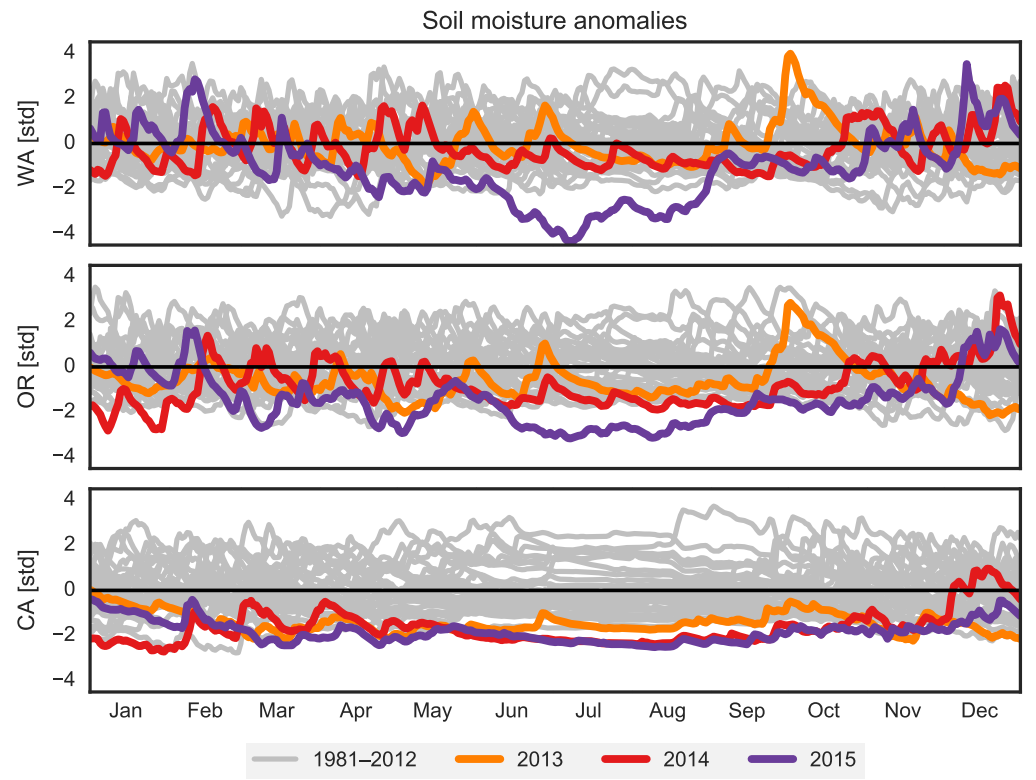

Fig. 5 Normalized soil moisture anomaly time series for each year and each analyzed state as estimated by CLM. The time series was normalized for every day of the year individually, i.e. the seasonal cycle was removed.

leads to rather dry conditions (i.e. by chance), the SSTs further aggravate these conditions. Figure 6 shows time series of the driest 5 th percentile of the simulations for each year, as well as their average from all years. The impacts of the SSTs are similar to those on the ensemble mean described above: while 2013 falls close to the average of all years, the first half of 2014 is rather dry. Most interestingly, a dry 2015 is among the driest from all years in both WA and OR from about April to late summer (Figure 6a-b), showing that part of the dryness was forced by SSTs. In contrast, CA did not exhibit particularly high risks of dry conditions in that year, with values in 2015 positioned around the mean of the 5th percentile from other years (Figure 6c), indicating that internal variability has been the most relevant factor in the dry soils in that state.

4.3 Impact of global warming on soil moisture

In order to investigate the impact of global warming on average June soil moisture, we check the difference between pre-industrial and current soil moisture conditions. Quantile-Quantile, or QQ-plots of June soil moisture averaged over each state, for the natural versus all forcings w@h ensemble (not shown), indicate no impact of climate change on average soil moisture conditions. 


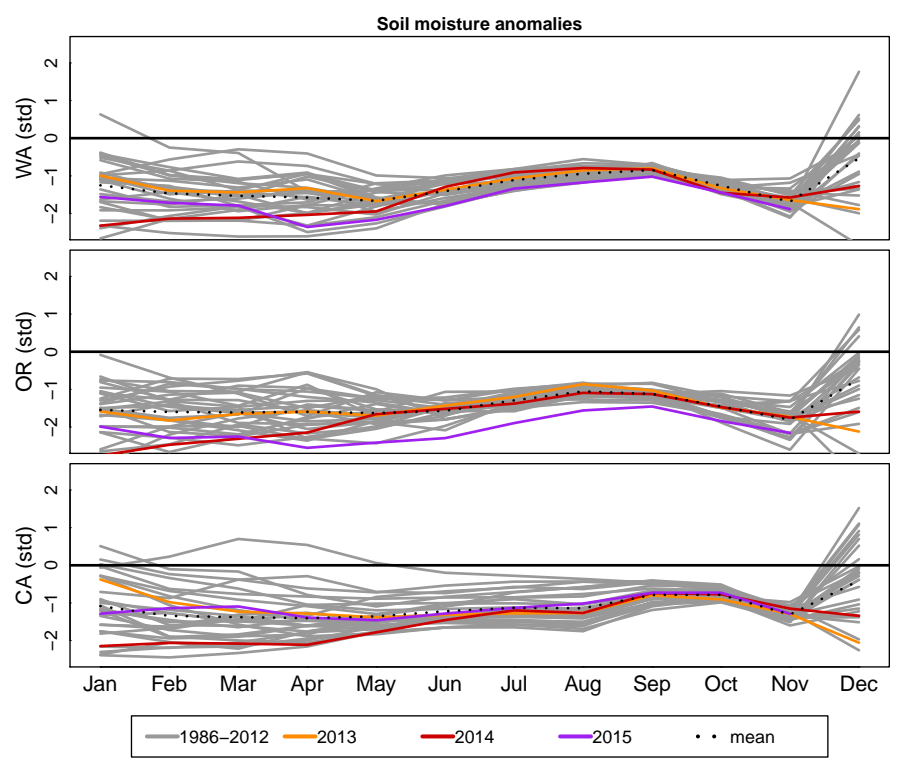

Fig. 6 Same as Fig. 5 but based on monthly soil moisture data and for the driest 5 th percentile of the ensemble for each year of w@h simulations. The average of all years is shown as a dotted black line. The normalisation is based on all years (with a constant number of randomly chosen simulations per year).

\section{Soil moisture-temperature coupling}

\subsection{Climatological coupling relation}

We quantify the climatological land-atmosphere coupling, i.e., the extent to which soil moisture influences the atmosphere, using the correlation between seasonally averaged air temperature and latent heat flux, see Supplement for details and figures (Figs. S2-S3). This coupling between temperature and soil moisture in CLM and w@h implies that the models represent well the associated feedbacks of soil moisture with temperature. The correlation maps confirm that CA is already in the dry regime, and that OR and WA are both in a transitional soil moisture regime.

The above correlations give insight in the climatological coupling regime. In the next paragraph we investigate the coupling between soil moisture and temperature in June 2015 in CLM data.

\subsection{Coupling in June 2015}

The relation between soil moisture and temperature can be investigated by studying different metrics. Below we show two different metrics that are investigated for the region with CLM data.

A first metric to investigate the soil moisture-temperature coupling is the $\pi$ metric developed by Miralles et al. (2012). When considering the impact of soil 


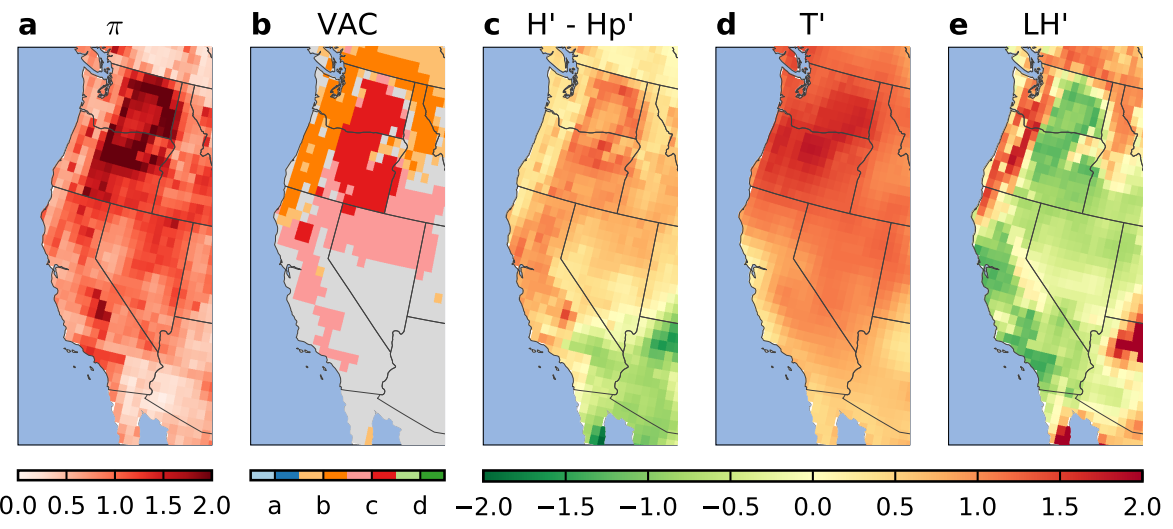

Fig. 7 Land atmosphere coupling metrics and anomalies for June 2015. (a) $\pi$ metric, (b), VAC index, (c) sensible heat flux minus potential sensible heat flux anomaly $H^{\prime}-H_{p}^{\prime}$, (d) temperature anomaly $T^{\prime}$ and (e) latent heat flux anomaly $L H^{\prime}$.

moisture on temperature (through the surface energy balance), one might simply look at the relation between daily evaporation and temperature. This introduces the complication that on a day-to-day basis, variability in evaporation or sensible heat flux is controlled by variability in atmospheric conditions (or potential evaporation) rather than soil moisture. Such variations can for instance be caused by differences in cloudiness or temperature. In order to correct for these variations, the $\pi$ metric consists of the product between standardized temperature anomaly ( $T^{\prime}$, expressing the extremity of the temperature) and the standardized anomaly in sensible heat flux corrected for the anomaly in sensible heat flux that would occur if soil moisture was sufficient for evaporation to occur at the potential rate $\left(H^{\prime}-H_{p}^{\prime}\right.$, for details see Miralles et al. 2012). A related metric to diagnose the soil moisture-temperature coupling at longer (climate) timescales is $\Pi$, see also the Supplement (Fig. S4) . $\Pi$ is calculated as the correlation between (daily) sensible heat flux and temperature, minus the correlation between the "potential" sensible heat flux (that would occur if evapotranspiration would occur under potential rates) and temperature.

Figure 7a,c,d shows the spatial distribution of $\pi$ and its two constituents $H^{\prime}-H_{p}^{\prime}$ and $T^{\prime}$. Panel a reveals that the coupling is strongest in WA and in northern OR. The spatial pattern of $\pi$ reflects variations in $H^{\prime}-H_{p}^{\prime}$ rather than $T^{\prime}$, whereas the overall magnitude of $\pi$ is determined by $T^{\prime}$ rather than $H^{\prime}-H_{p}^{\prime}$. This indicates that anomalies in the surface energy balance likely contributed locally to the temperature extremes, but they are not the sole mechanism that can explain the temperature extremes. Large positive temperature anomalies can be found over the whole of the Western US and are thus much more widespread than strong anomalies in the surface energy balance. Note that the absolute values for $\pi$ are lower than those reported for the 2003 heatwave in Europe, the 2006 heatwave in the central US, and the 2010 Russian heatwave (Miralles et al. 2012, 2014). This can be explained by the longer (monthly) time period considered in Figure 7 , whereas the other studies focussed solely on the period with maximum temperature anomalies. 
The above $\pi$ metric is on a monthly scale. Shorter timescales (weekly and daily) are shown and investigated in the Supplement (Figs. S5-S6). From that analysis we conclude that the weekly $\pi$ metric was stronger during the June 2015 event in WA and OR than any other time in the period 1979-2014.

A second metric to explore the land-atmosphere coupling is the Vegetation Atmosphere Coupling Index (VAC; Zscheischler et al. 2015). It identifies regions where large anomalies of $\mathrm{T}$ and $\mathrm{LH}$ occur at the same time. This yields four combinations of negative and positive anomalies in $\mathrm{T}$ and $\mathrm{LH}$. If anomalies of both variables are larger than one standard deviation, we use 'light' colors in the figures; if they are larger than two standard deviations, 'dark' colors are used. Of the four coupling regimes, only two are relevant here: $\mathrm{VAC}_{b}$ and $\mathrm{VAC}_{c}$. $\mathrm{VAC}_{b}$ (light and dark orange) denotes concurrent positive anomalies in $\mathrm{T}$ and $\mathrm{LH}$, indicating a drying of the soil and atmospheric control. For $\mathrm{VAC}_{c}$ (light and dark red), positive anomalies in $\mathrm{T}$ coincide with negative anomalies in LH, indicating dry soils and a coupling controlled by the land surface.

VAC for monthly anomalies in T and LH is shown in Figure 7 (e). VAC identifies the interior of $\mathrm{WA}$ and $\mathrm{OR}$ as a region of strong land-atmosphere coupling $\left(\mathrm{VAC}_{c}\right)$, in close agreement to $\pi$. Additionally, it shows a ring of $\mathrm{VAC}_{b}$ indicating a strong loss of soil moisture due to evapotranspiration.

Both metrics agree in the strong coupling between soil moisture and temperature in June 2015 in WA and also in OR. This strengthens the conclusion that soil moisture played an important role in June 2015 in WA and OR.

\subsection{Soil moisture and return periods for June 2015 temperature extremes}

The forecast of May 2015 of the EUROSIP forecast system (European multi-model Seasonal to Inter-annual Prediction, ECMWF) already showed positive temperature anomalies for the summer of 2015 in the western US states, up to $1-2{ }^{\circ} \mathrm{C}$ above normal in WA. In this section we further investigate the preconditioning of temperature extremes with w@h data. Furthermore, we quantify the relation between temperature and soil moisture in CLM.

We investigate the influence of wet versus dry soils on state-averaged June temperatures in the three states, by comparing the dry half of the $2015 \mathrm{w} @ \mathrm{~h}$ ensemble members with the wet half (from about 740 simulations with all forcings for 2015). The distributions of June temperatures for all ensemble members and for ensemble members conditioned on wet/dry May and wet/dry June monthly soil moisture are plotted in Fig. 8, using a smoothing bandwidth of 0.4. The strong coupling between wet/dry June soils and June temperatures is clearly visible for WA and OR: dry soils are associated with higher temperatures. Both the mean temperature and the hot tail become hotter for dry soils.

It should be noted that this strong relationship is not necessarily a causal effect, as it may also simply emerge from the difference between ensemble members with more clouds, rain and thus colder temperature and wetter soils, and those with clear skies, leading to warmer temperatures and soil drying. The result from preconditioning on wet/dry May soil moisture is in the same direction, although somewhat weaker, as expected as soil moisture slowly loses memory. This better isolates possible causal effects and shows that, in WA and OR, the preconditioning of May soil moisture impacts June temperature. Note that the small blob found 


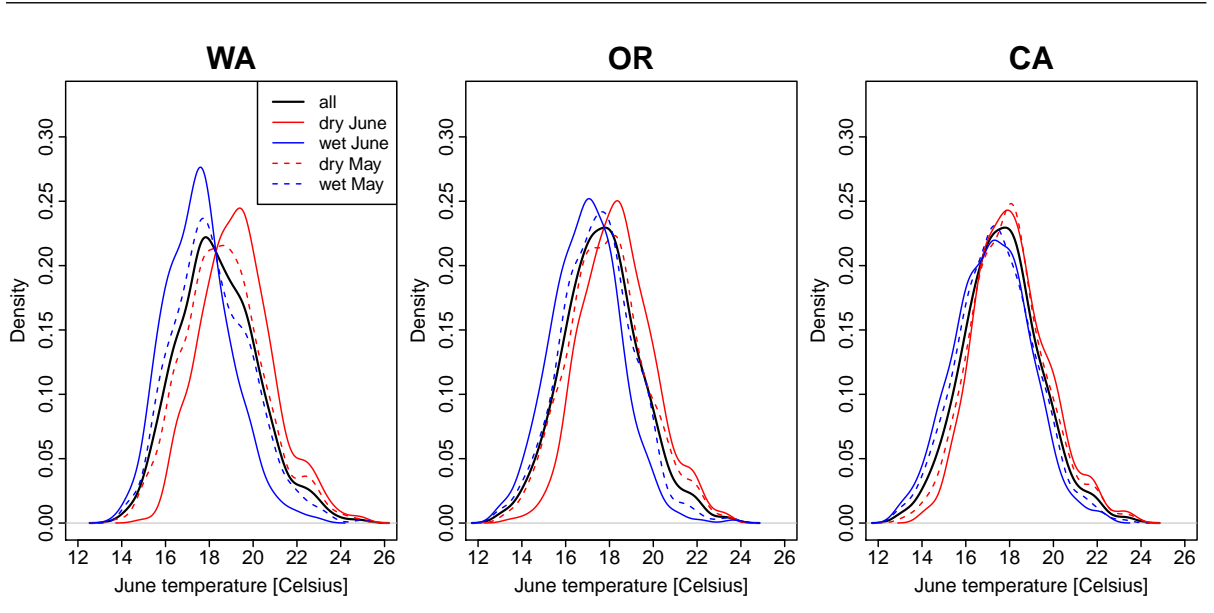

Fig. 8 PDF of June 2015 temperature conditioned on soil moisture: all simulations (black), wet and dry soils in May (blue/red dotted lines) and wet and dry soils in June (blue/red continuous lines) for w@h 2015 all forcings simulations, for the three states.

in the hot tail of the dry distributions is due to the smoothing and should not be over-interpreted.

The general conclusion from this is that in WA and OR there is no longer a linear relation between local temperature and the GMST, as the coupling between temperature and soil moisture plays an important role as well. Therefore, we will include soil moisture in our investigation of the high temperatures.

From the quantification of the linear relation between temperature and GMST we see that the contribution of GMST is probably not enough to explain the high temperatures (Section 3). We now quantify the relation of temperature with soil moisture in CLM. Whan et al. (2015) showed that using soil moisture as a covariate in extreme value analysis can provide an indication of the increase in temperature expected between wet and dry soil conditions. Here, we similarly assess how soil moisture influences the distribution of monthly temperature extremes for the Western states.

The investigation on the coupling between temperature and soil moisture, using antecedent soil moisture conditions (e.g., May) gives an indication if the extreme temperatures are due to a pre-existing soil moisture anomaly, in other words if soil moisture is a good predictor of temperature. We find that this is indeed the case. However, we are not only interested in the predictability of temperature from antecedent soil moisture, since dry May conditions do not guarantee low soil moisture in the next month. In order to obtain extremely high temperatures in June, soil moisture also needs to stay low in June. If there is precipitation in June, temperatures will be lower and the soil will be less dry. As we are interested in the highest temperatures, we take simultaneous measures of soil moisture and temperature, as this includes both information on additional temperature amplification due to feedbacks and amplification of negative soil moisture anomalies due to weather conditions. In subsequent analyses we therefore take June soil moisture as a covariate for June temperature.

For the analysis of the influence of soil moisture on temperature we first detrend the CLM monthly temperatures. This gives, at first order, insight into the 
relative contribution of soil moisture on temperature anomalies, separate from global warming. There is no significant trend in soil moisture. Then, we again fit a Gaussian distribution to the detrended temperature, this time with soil moisture as the linear covariate for the mean of the distribution.

We have to choose soil moisture conditions representative of a dry and a wet regime to estimate return periods of temperature conditional on soil moisture. We choose the reference dry soil moisture year to be 2015, as we want to investigate the influence of this year's soil moisture on temperature. For the wet regime we use 1980, as this was a year with a relatively wet soil in all three states. For WA and OR it is the 6 th wettest year of the time series, and for CA the 7 th wettest year. The fit (see Fig. 9) shows again that the summer temperatures of 2015 were indeed extreme in WA and OR. The extrapolated temperature/drought lines explain a large part of the anomalies of June 2015, so their extremity is explained to a large extent by the dryness. Hence, the return periods are not as extreme when we include soil moisture as when we only look at the effect of the global mean temperature rise, with return periods of the June 2015 value of 4 years for WA (95\% confidence interval 2-47), 43 years for OR (95\% confidence interval 7-1500) and 3 years for CA (95\% confidence interval 2-6) for years with dry soil moisture. In a year with high soil moisture values, a temperature event like this would have been very unlikely.

Note that we do not state that soil moisture is an explanation for the temperature. The positive feedback loop between low soil moisture and heat enhances the high temperatures. The causal connection between temperature and soil moisture is also present when end-of-May soil moisture is used instead of June soil moisture (not shown).

A direct comparison of these return periods with the return periods of observations of local T2m extremes is not possible as, for the analysis with GMST as a covariate, we use the long GISTEMP dataset. However, the correlation of CLM temperature and GISTEMP temperature is high (0.99, 0.98 and 0.96 for WA, OR and CA respectively). An analysis of CLM temperatures with GMST as a covariate gives return periods for 2015 in the same order of magnitude as the analysis with GISTEMP temperatures as mentioned in Section 3. The same holds for an analysis of GISTEMP temperature against CLM soil moisture.

A similar analysis in which we replace the detrended temperatures with actual temperatures but still take soil moisture as a covariate shows the combined effect of global warming and wet/dry soils. A comparison with the detrended analysis then gives, to first order, insight in the relative contributions of global warming and drought separately. For WA, the return period of the (not-detrended) temperature extreme is in the order of 24 years in case of dry soils, whereas the detrended temperature anomaly has a return period of 4 years in case of dry soils. The difference due to detrended temperatures is thus of the order of a factor of 6 , whereas the difference in return period between wet and dry June soils is very large (i.e. $>10^{7}$ for WA and OR). For OR, the detrended and actual return periods are 325 and 43 (which gives a difference of a factor of 8 ). In CA, the difference is not significant. This means that, in WA and OR, the dry soil has a larger influence on the temperature extreme than the increased GMST.

From the relation between soil moisture and temperature, we conclude that the return periods including the effects of soil moisture are not as extreme as the return periods including only the effect of GMST rise. The June 2015 values fit 
WA
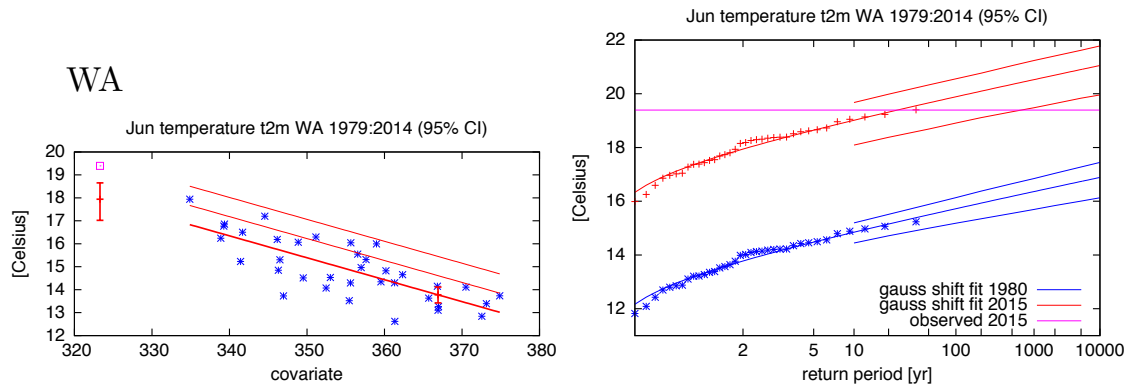

OR
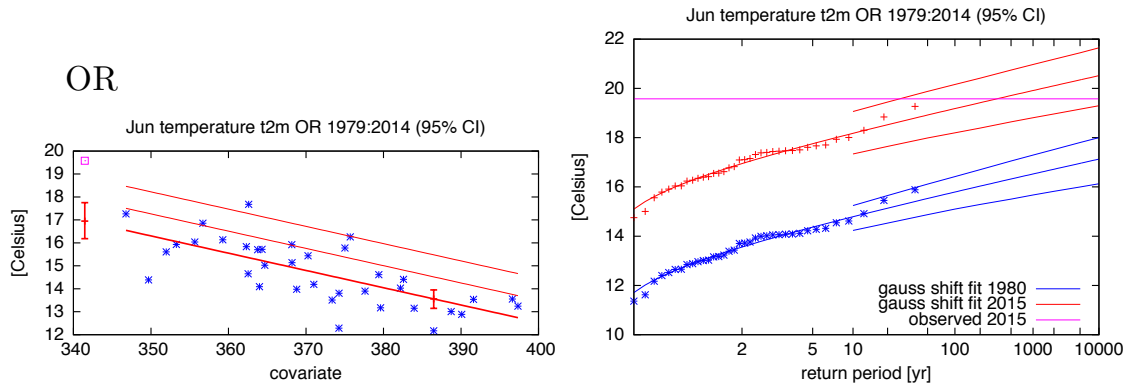

CA
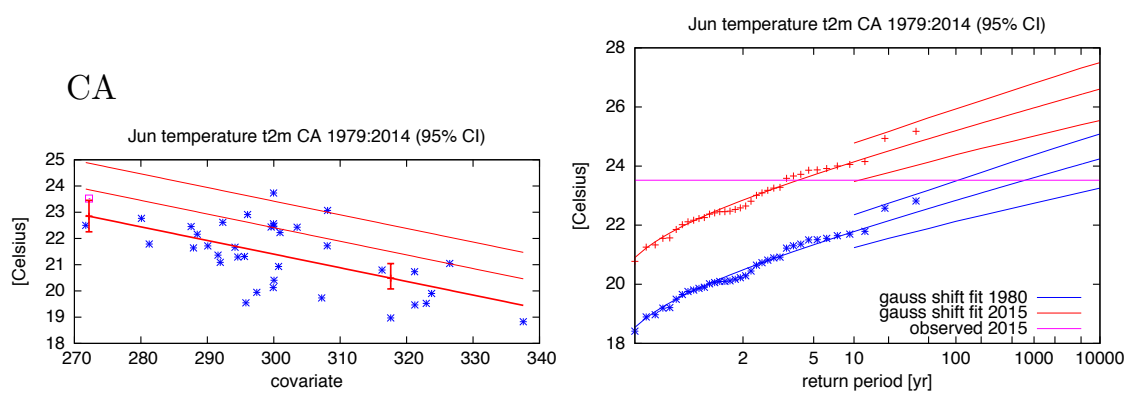

Fig. 9 Gaussian distribution that shifts with the monthly soil moisture content. Left: Monthly detrended CLM June temperature against the soil moisture value $(1 \mathrm{~m})$ of the same month. The thick line denotes the location parameter and the thin lines are 1 sigma and 2 sigma above. The purple box shows the 2015 value, which was not used in the calculations, and the two vertical red lines show the $95 \%$ contour interval at the level of the 1980 and 2015 climates. Right: Return periods for temperatures shifted upwards towards dry soil conditions (red line, 2015) and for temperatures shifted downwards towards wetter soil conditions (blue line, 1980).

well in the extrapolated temperature/drought lines, whereas in a year with high soil moisture values a temperature event like 2015 would have been very unlikely. The magnitude of the temperature anomaly thus fits well in the expected increase in temperature in the presence of dry soils, in a region that is in transition from a wet to dry regime.

Arguably, there are some differences between the states both in terms of the extremity of the temperatures as well as their impacts. Although the temperature anomaly was very high in CA, it was not as extreme as in WA or OR. Furthermore, CA was already in the dry regime in the summer months, whereas WA and OR are in the transitional regime. In terms of resilience and adaptation we have to keep in mind that in CA most of the farmlands are irrigated, but in WA and OR 
this is much less the case. In addition, there is a particularly high prevalence of air conditioning in inland CA. Therefore, the impact of the extreme temperature of June 2015 may well have been much larger in WA and OR than in CA.

\section{Conclusions}

The Western US states WA, OR and CA experienced extremely high temperatures in June 2015, especially WA and OR. The state-averaged June temperatures were record high, even in the long GISTEMP dataset. Fitting a Gaussian distribution to the data, shifting with GMST as a covariate, showed that the June 2015 temperature anomalies were so extreme that they cannot be explained with global warming alone. The w@h ensemble deviates from a Gaussian distribution for the highest temperature values.

Models driven by reanalysis show that soil moisture was very low at the time of the event. The soil moisture-temperature coupling metrics $\pi$ and VAC both show that there is strong coupling between soil moisture and temperature in June 2015 in WA and OR. This means that, whereas CA is already in the dry regime, OR and WA are both in a transitional soil moisture regime where soil moisture changes affect temperature.

A PDF of w@h June temperature conditioned on soil moisture shows that for high temperatures there is no longer a linear relation between regional temperature and the global mean surface temperature. Both the mean temperature and the hot tail become hotter for dry soils, especially in WA and OR. From this we conclude that coupling between temperature and soil moisture plays an important role as well.

From the relation between soil moisture and temperature found above we hypothesized that we need to take soil moisture into account in investigating return periods of extreme temperatures. Using soil moisture as a covariate in the Gaussian model fit provides an indication of the magnitude increase in temperature expected between specified wet and dry conditions after taking the trend into account linearly. The June 2015 temperature values fit well in the extrapolated temperature/drought lines from a gaussian fit of temperatures with soil moisture as a covariate. The temperature anomalies in WA and OR thus fit well in the expected increase in temperature in the presence of dry soils, in regions that are in the transition from a wet regime towards a dry regime. In CA we find that, because the region is already in the dry soil moisture regime, the necessity of taking soil moisture changes into account is of lower importance.

We thus find that, on top of the expected global warming trend, the dry summer also contributed to the temperature extreme, with the remainder due to weather fluctuations (that were made more likely due to the SST pattern of this summer).

The conclusions imply that for all regions that are in the transition zone from wet to dry, soil moisture is an important factor in temperature extremes. This may also become the case for regions that will be in such a transition in future, as temperatures continue to rise. Similar or even warmer events can then be expected more often in the future, and events can be warmer than expected from the local trend with respect to GMST alone, due to the coupling with soil moisture (Vogel et al. 2017). 
The feedback between soil moisture and temperature is a two-way coupling: 3 soil moisture affects temperature and vice versa. In a wet-to-dry transition zone, 4 the higher temperatures that are reached due to anthropogenic climate change 5 may lead to drier conditions during hot periods. Therefore agricultural droughts may become more common. Besides, in those (future) transition zones, extreme 7 temperatures might become more extreme than expected from the rising GMST alone; they will be influenced by drier soils as well.

An additional factor that may well have contributed to the summer drought is reduced water storage in snow. According to Mote et al. (2016a), climate change reduced snow accumulation on the mountains, exacerbating the drought. Global temperature changes may lead to a change in the partitioning of precipitation falling as rain or snow. Increased winter temperatures will lead to reduced snowpacks (even if precipitation increases, it is more likely to fall as rain than snow), and increased spring temperatures will lead to earlier melting of the remaining snowpacks, with peak streamflows from snowmelt occurring well before the dry summer season. Both effects will lead to a reduction in high altitude snow storage and reduced water availability for the summer. Excess liquid water, that in the past would have fallen as snow, may also need to be released from storage earlier in the year if there is insufficient capacity to dam it in liquid form. These conditions will occur more frequently in the future, leading to more extreme summer temperatures than expected from a simple shift of the distribution with the global temperature trend.

In this study we limited the areal event definition to three individual states. Results for sub-regions might be slightly different. However, by focusing on a state as a whole, we select a region which is not defined by the event?s boundaries. This is necessary to avoid creating extreme events by construction and permits a more general interpretation of the results. In addition, results based on state boundaries can be easily compared with other (future) studies.

We investigated the instantaneous relation between soil moisture and temperature, which includes effects of the positive feedback between low soil moisture and heat that enhances the high temperatures. We did not disentangle the feedback by investigating the response of temperature to soil moisture or soil moisture to temperature separately. For this a modelling approach is required in which the processes can be individually controlled (Hauser et al. 2016). This was beyond the scope of this study.

An assumption we made in our analysis is that there is a linear dependence of temperature and soil moisture on the (low pass filtered) global mean temperature. This is represented by a linear shift in the location parameter of the Gaussian fits. For temperature, this has been proposed and tested in earlier studies. The dependence of temperature on soil moisture is not yet confirmed by many studies. For soil moisture it probably also depends on whether the region is wet, in transition from wet to dry, or dry. Here, in line with studies on temperature, we choose for the simplest assumption, a linear shift of the PDF depending on soil moisture, to keep method simplest for all three regions. Future studies can focus more on investigating this assumption.

Acknowledgements We would like to thank all of the volunteers who have donated their computing time to climateprediction.net and weather@home. We thank our colleagues at the Oxford eResearch Centre: A. Bowery, M. Rashid, S. Sparrow and D. Wallom for their technical 
expertise. We also thank the Met Office Hadley Centre PRECIS team for their technical and scientific support for the development and application of weather@home. We extend our appreciation to Sonia Seneviratne for her suggestions and feedback. This project was supported by the World Weather Attribution initiative and the EU project EUCLEIA under Grant Agreement 607085.

\section{References}

AghaKouchak, A., D. Feldman, M. Hoerling, T. Huxman, and J. Lund. 2015. Recognize anthropogenic drought. Nature 524: 409-411. doi:10.1038/524409a.

Balsamo, G., C. Albergel, A. Beljaars, S. Boussetta, E. Brun, H. Cloke, D. Dee, E. Dutra, J. Muñoz Sabater, F. Pappenberger, P. de Rosnay, T. Stockdale, and F. Vitart. 2015. Era-interim/land: a global land surface reanalysis data set. Hydrology and Earth System Sciences 19 (1): 389-407. doi:10.5194/hess-19-389-2015. http://www.hydrol-earthsyst-sci.net/19/389/2015/.

Cheng, Linyin, Martin Hoerling, Amir AghaKouchak, Ben Livneh, Xiao-Wei Quan, and Jon Eischeid. 2016. How has human-induced climate change affected california drought risk? Journal of Climate 29 (1): 111-120.

Cowan, Tim, Ariaan Purich, Sarah Perkins, Alexandre Pezza, Ghyslaine Boschat, and Katherine Sadler. 2014. More frequent, longer, and hotter heat waves for australia in the twentyfirst century. Journal of Climate 27 (15): 5851-5871. doi:10.1175/JCLI-D-14-00092.1. http://dx.doi.org/10.1175/JCLI-D-14-00092.1.

Dee, D. P., S. M. Uppala, A. J. Simmons, P. Berrisford, P. Poli, S. Kobayashi, U. Andrae, M. A. Balmaseda, G. Balsamo, P. Bauer, P. Bechtold, A. C. M. Beljaars, L. van de Berg, J. Bidlot, N. Bormann, C. Delsol, R. Dragani, M. Fuentes, A. J. Geer, L. Haimberger, S. B. Healy, H. Hersbach, E. V. Hlm, L. Isaksen, P. Kllberg, M. Khler, M. Matricardi, A. P. McNally, B. M. Monge-Sanz, J. J. Morcrette, B. K. Park, C. Peubey, P. de Rosnay, C. Tavolato, J. N. Thpaut, and F. Vitart. 2011. The era-interim reanalysis: configuration and performance of the data assimilation system. Quarterly Journal of the Royal Meteorological Society 137 (656): 553-597. doi:10.1002/qj.828. http://dx.doi.org/10.1002/qj.828.

Diffenbaugh, Noah S., Daniel L. Swain, and Danielle Touma. 2015. Anthropogenic warming has increased drought risk in california. Proceedings of the $\mathrm{Na}$ tional Academy of Sciences 112 (13): 3931-3936. doi:10.1073/pnas.1422385112. http://www.pnas.org/content/112/13/3931.abstract.

Donat, M. G., L. V. Alexander, H. Yang, I. Durre, R. Vose, R. J. H. Dunn, K. M. Willett, E. Aguilar, M. Brunet, J. Caesar, B. Hewitson, C. Jack, A. M. G. Klein Tank, A. C. Kruger, J. Marengo, T. C. Peterson, M. Renom, C. Oria Rojas, M. Rusticucci, J. Salinger, A. S. Elrayah, S. S. Sekele, A. K. Srivastava, B. Trewin, C. Villarroel, L. A. Vincent, P. Zhai, X. Zhang, and S. Kitching. 2013. Updated analyses of temperature and precipitation extreme indices since the beginning of the twentieth century: The hadex 2 dataset. Journal of Geophysical Research: Atmospheres 118 (5): 2098-2118. doi:10.1002/jgrd.50150. http://dx.doi.org/10.1002/jgrd.50150.

Donlon, Craig J., Matthew Martin, John Stark, Jonah Roberts-Jones, Emma Fiedler, and Werenfrid Wimmer. 2012. The operational sea surface temperature and sea ice analysis (ostia) system. Remote Sens Environ 116: 140-158. doi:http://dx.doi.org/10.1016/j.rse.2010.10.017. Advanced Along Track Scanning Radiometer(AATSR) Special Issue. http://www.sciencedirect.com/science/article/pii/S0034425711002197.

Fischer, E. M., S. I. Seneviratne, P. L. Vidale, D. Lüthi, and C. Schär. 2007. Soil moisture-atmosphere interactions during the 2003 european summer heat wave. Journal of Climate 20 (20): 5081-5099. doi:10.1175/JCLI4288.1. ISBN 0894-8755. http://dx.doi.org/10.1175/JCLI4288.1.

Grize, Leticia, Anke Huss, Oliver Thommen, Christian Schindler, and Charlotte BraunFahrlander. 2005. Heat wave 2003 and mortality in switzerland. Swiss Med Wkly 135 (13-14): 200-205. doi:2005/13/smw-11009.

Guillod, Benoit P., Boris Orlowsky, Diego G. Miralles, Adriaan J. Teuling, and Sonia I. Seneviratne. 2015. Reconciling spatial and temporal soil moisture effects on afternoon rainfall. Nat. Commun. 6: 7443. http://dx.doi.org/10.1038/ncomms7443. 
Guirguis, Kristen, Alexander Gershunov, Alexander Tardy, and Rupa Basu. 2014. The impact of recent heat waves on human health in california. Journal of Applied Meteorology and Climatology 53 (1): 3-19. doi:10.1175/JAMC-D-13-0130.1. ISBN 1558-8424. http://dx.doi.org/10.1175/JAMC-D-13-0130.1.

Hansen, J., R. Ruedy, M. Sato, and K. Lo. 2010. Global surface temperature change. Rev. Geophys. 48: 4004. doi:DOI 10.1029/2010RG000345.

Hauser, Mathias, Ren Orth, and Sonia I. Seneviratne. 2016. Role of soil moisture versus recent climate change for the 2010 heat wave in western russia. Geophysical Research Letters. doi:10.1002/2016GL068036. 2016GL068036. http://dx.doi.org/10.1002/2016GL068036.

Li, Sihan, Philip W. Mote, David E. Rupp, Dean Vickers, Roberto Mera, and Myles Allen. 2015. Evaluation of a Regional Climate Modeling Effort for the Western United States Using a Superensemble from Weather@home. J Clim 28 (19): 7470-7488. doi:10.1175/JCLI-D-1400808.1. http://dx.doi.org/10.1175/JCLI-D-14-00808.1.

Lobell, David B., and Cline Bonfils. 2008. The effect of irrigation on regional temperatures: A spatial and temporal analysis of trends in california, 1934?2002. Journal of Climate 21 (10): 2063-2071. doi:10.1175/2007JCLI1755.1. http://dx.doi.org/10.1175/2007JCLI1755.1.

Massey, N., R. Jones, F. E. L. Otto, T. Aina, S. Wilson, J. M. Murphy, D. Hassell, Y. H. Yamazaki, and M. R. Allen. 2015. weather@home - development and validation of a very large ensemble modelling system for probabilistic event attribution. Quart. J. Roy. Meteor. Soc. 141 (690): 1528-1545. doi:10.1002/qj.2455. http://dx.doi.org/10.1002/qj.2455.

Meehl, Gerald A., and Claudia Tebaldi. 2004. More intense, more frequent, and longer lasting heat waves in the 21st century. Science 305 (5686): 994-997. doi:10.1126/science.1098704. http://science.sciencemag.org/content/305/5686/994.

Min, E., W. Hazeleger, G. J. van Oldenborgh, and A. Sterl. 2013. Evaluation of trends in high temperature extremes in north-western Europe in regional climate models. Environ. Res. Lett. 8 (1): 014011. doi:10.1088/1748-9326/8/1/014011.

Miralles, D. G., M. J. van den Berg, A. J. Teuling, and R. A. M. de Jeu. 2012. Soil moisturetemperature coupling: A multiscale observational analysis. Geophysical Research Letters 39 (21): . doi:10.1029/2012GL053703. L21707. http://dx.doi.org/10.1029/2012GL053703.

Miralles, Diego G., Adriaan J. Teuling, Chiel C. van Heerwaarden, and Jordi Vila-Guerau de Arellano. 2014. Mega-heatwave temperatures due to combined soil desiccation and atmospheric heat accumulation. Nature Geosci 7 (5): 345-349.

Mote, P., D. Rupp, S. Li, D. Sharp, F. Otto, P. Uhe, M. Xiao, D. Lettenmaier, H. Cullen, and M. Allen. 2016a. Perspectives on the causes of exceptionally low 2015 snowpack in the western United States. Geophysical Research Letters 43 (20).

Mote, Philip W., Myles R. Allen, Richard G. Jones, Sihan Li, Roberto Mera, David E. Rupp, Ahmed Salahuddin, and Dean Vickers. 2016b. Superensemble regional climate modeling for the western united states. Bull Am Meteorol Soc 97 (2): 203-215. doi:10.1175/BAMSD-14-00090.1. http://dx.doi.org/10.1175/BAMS-D-14-00090.1.

Oleson, K. W., D. M. Lawrence, B. Gordon, M. G. Flanner, E. Kluzek, J. Peter, S. Levis, S. C. Swenson, E. Thornton, J. Feddema, et al. 2010. Technical description of version 4.0 of the community land model (clm).

Orth, Rene, and Sonia I Seneviratne. 2015. Introduction of a simple-model-based land surface dataset for europe. Environmental Research Letters 10 (4): 044012. http://stacks.iop.org/1748-9326/10/i=4/a=044012.

Otto, F. E. L., N. Massey, G. J. van Oldenborgh, R. G. Jones, and M. R. Allen. 2012. Reconciling two approaches to attribution of the 2010 russian heat wave. Geophys. Res. Lett. 39 (4): 04702. doi:10.1029/2011GL050422. ISBN 0094-8276.

Perkins, Sarah E., Sophie C. Lewis, Andrew D. King, and Lisa V. Alexander. 2014. Increased simulated risk of the hot australian summer of 2012/13 due to anthropogenic activity as measured by heat wave frequency and intensity. Bulletin of the American Meteorological Society 95 (9): 34-37.

Rupp, David E., Sihan Li, Neil Massey, Sarah N. Sparrow, Philip W. Mote, and Myles Allen. 2015. Anthropogenic influence on the changing likelihood of an exceptionally warm summer in texas, 2011. Geophysical Research Letters 42 (7): 2392-2400. doi:10.1002/2014GL062683. 2014GL062683. http://dx.doi.org/10.1002/2014GL062683.

Seager, Richard, and Martin Hoerling. 2014. Atmosphere and ocean origins of north american droughts. Journal of Climate 27 (12): 4581-4606.

Seager, Richard, Martin Hoerling, Siegfried Schubert, Hailan Wang, Bradfield Lyon, Arun Kumar, Jennifer Nakamura, and Naomi Henderson. 2015. Causes of the 2011?14 california 
drought. Journal of Climate 28 (18): 6997-7024.

Seneviratne, S. I., T. Corti, E. L. Davin, M. Hirschi, E. B. Jaeger, I. Lehner, B. Orlowsky, and A. J. Teuling. 2010. Investigating soil moisture-climate interactions in a changing climate: A review. Earth Science Reviews 99: 125-161. doi:10.1016/j.earscirev.2010.02.004.

Stegehuis, Annemiek I, Robert Vautard, Philippe Ciais, Adriaan J Teuling, Martin Jung, and Pascal Yiou. 2013. Summer temperatures in europe and land heat fluxes in observationbased data and regional climate model simulations. Climate dynamics 41 (2): 455-477.

Stocker, T. F., et al., eds. 2013. Climate change 2013: The physical science basis. Cambridge, U.K. and New York, U.S.A.: Cambridge University Press.

Sun, Ying, Xuebin Zhang, Francis W. Zwiers, Lianchun Song, Hui Wan, Ting Hu, Hong Yin, and Guoyu Ren. 2014. Rapid increase in the risk of extreme summer heat in eastern china. Nature Clim. Change 4: 1082-1085. doi:doi:10.1038/nclimate2410.

Swain, Daniel L. 2015. A tale of two california droughts: Lessons amidst record warmth and dryness in a region of complex physical and human geography. Geophysical Research Letters 42 (22): 9999-10003. doi:10.1002/2015GL066628. 2015GL066628. http://dx.doi.org/10.1002/2015GL066628.

Taylor, Karl E., Ronald J. Stouffer, and Gerald A. Meehl. 2012. An Overview of CMIP5 and the Experiment Design. Bull. Am. Meteorol. Soc. 93 (4): 485-498. doi:10.1175/BAMS-D11-00094.1. http://dx.doi.org/10.1175/BAMS-D-11-00094.1.

Van Loon, A. F., T. Gleeson, J. Clark, A. I. J. M. van Dijk, K. Stahl, J. Hannaford, G. Di Baldassarre, A. J. Teuling, L. N. Tallaksen, R. Uijlenhoet, D. M. Hannah, J. Sheffield, M. Svoboda, B. Verbeiren, T. Wagener, S. Rangecroft, N. Wanders, and H. A. J. van Lanen. 2016. Drought in the anthropocene. Nature Geoscience 9: 89-91. doi:10.1038/ngeo2646. http://dx.doi.org/10.1038/ngeo2646.

van Oldenborgh, G. J. 2007. How unusual was autumn 2006 in Europe? Clim. Past 3 (4): 659-668. doi:10.5194/cp-3-659-2007. http://www.clim-past.net/3/659/2007/.

Vogel, M. M., R. Orth, F. Cheruy, S. Hagemann, R. Lorenz, B. J. J. M. van den Hurk, and S. I. Seneviratne. 2017. Regional amplification of projected changes in extreme temperatures strongly controlled by soil moisture-temperature feedbacks. Geophysical Research Letters 44 (3): 1511-1519. doi:10.1002/2016GL071235. 2016GL071235. http://dx.doi.org/10.1002/2016GL071235.

Whan, Kirien, Jakob Zscheischler, Rene Orth, Mxolisi Shongwe, Mohammad Rahimi, Ernest O. Asare, and Sonia I. Seneviratne. 2015. Impact of soil moisture on extreme maximum temperatures in europe. Weather and Climate Extremes 9: 57-67. doi:http://dx.doi.org/10.1016/j.wace.2015.05.001. The World Climate Research Program Grand Challenge on Extremes ? WCRPICTP Summer School on Attribution and Prediction of Extreme Events. http://www.sciencedirect.com/science/article/pii/S2212094715000201.

Williams, A. Park, Richard Seager, John T. Abatzoglou, Benjamin I. Cook, Jason E. Smerdon, and Edward R. Cook. 2015. Contribution of anthropogenic warming to california drought during 2012?2014. Geophysical Research Letters 42 (16): 6819-6828. doi:10.1002/2015GL064924. 2015GL064924. http://dx.doi.org/10.1002/2015GL064924.

Yin, Dongqin, Michael L. Roderick, Guy Leech, Fubao Sun, and Yuefei Huang. 2014. The contribution of reduction in evaporative cooling to higher surface air temperatures during drought. Geophysical Research Letters 41 (22): 7891-7897. doi:10.1002/2014GL062039. 2014GL062039. http://dx.doi.org/10.1002/2014GL062039.

Zscheischler, Jakob, Ren Orth, and Sonia I. Seneviratne. 2015. A submonthly database for detecting changes in vegetation-atmosphere coupling. Geophysical Research Letters 42 (22): 9816-9824. doi:10.1002/2015GL066563. 2015GL066563. http://dx.doi.org/10.1002/2015GL066563. 